\title{
PERFORMANCE OF ZINC-DIFATTYALKYLDITHYOCARBAMATE AS ANTI-FRICTION/ANTI-WEAR LUBRICANT ADDITIVES
}

\author{
Komar Sutriah ${ }^{1,2, *}$, Zainal Alim Mas'ud ${ }^{1,2}$, Tun Tedja Irawadi ${ }^{1,2}$, and Mohammad Khotib ${ }^{1,2}$ \\ ${ }^{1}$ Department of Chemistry, Faculty of Mathematic and Natural Sciences, Bogor Agricultural University, \\ Darmaga Campus, Fapet Building W2 Lt 4-5, Agatis Street, Bogor 16680, Indonesia \\ ${ }^{2}$ Integrated Laboratory, Bogor Agricultural University, Baranangsiang Campus, \\ Pajajaran Street, Bogor 16144, Indonesia
}

Received February 28, 2014; Accepted March 5, 2014

\begin{abstract}
Dithyocarbamate is an organosulphur compound that has long been known and widely applied in various fields, including in agriculture and industry. Several variants of synthesized vegetable oil-based Zincdifattyalkyldithyocarbamate were tested its anti-friction/anti-wear performance on four ball machine using the method of ASTM-D2783. Anti-friction/anti-wear test to six of additive variants of Zinc-difattyalkyldithyocarbamate at doses of $1.2 \%$ indicated that all variants of the product has welding point value higher than the lube base oil lubricant HVI 60, and from US Steel 136 standard for Hydraulic lubricants, but only two additive variants of Zinc-bis(lauryl palmityl)dithyocarbamate and Zinc-bis(lauryl oleyl)dithyocarbamate which has a larger load wear index value than the standard, and meet the criteria as an additive extreme pressure according to US steel 136 standard. Zincbis(lauryl palmityl)dithyocarbamate is an additive variant with the best performance, meet bi-functional lubricant additives criteria, as anti-friction/anti-wear and antioxidant additive.
\end{abstract}

Keywords: anti-friction/anti-wear; Zinc-difattyalkyldithyocarbamate

\section{ABSTRAK}

Dithyocarbamate merupakan senyawa organosulfur yang telah lama dikenal dan banyak diaplikasikan di berbagai bidang, termasuk di bidang pertanian dan industri. Beberapa varian senyawa kompleks Zincdifattyalkyldithyocarbamate berbasis minyak nabati yang disintesis, diuji kinerja antifriksi/antiwearnya pada mesin four ball menggunakan metode ASTM-D2783. Uji antifriksi/antiwear terhadap enam varian aditif kompleks Zincdifattyalkyldithyocarbamate pada dosis 1,2\%, menunjukkan bahwa seluruh varian produk memiliki nilai welding point yang lebih tinggi dari pelumas dasar lube base oil HVI 60, dan dari standar US Steel 136 untuk pelumas hidraulik, tetapi hanya dua varian aditif Zinc-bis(laurylpalmityl)dithiocarbamate dan Zinc-bis(lauryloleyl)dithiocarbamate yang memiliki nilai load wear index yang lebih besar dari standar tersebut, dan memenuhi kriteria sebagai aditif extreme pressure menurut standar US steel 136. Zinc-bis(laurylpalmityl)dithiocarbamate merupakan varian aditif dengan kinerja terbaik, memenuhi kriteria aditif pelumas bifungsi, sebagai aditif antifriksi/antiwear dan antioksidan.

Kata Kunci: antifriksi/antiwear; Zinc-difattyalkyldithyocarbamate

\section{INTRODUCTION}

Lubrication process is inevitable on the phenomenon of surface/interface. Two surfaces which move against one another or both of surfaces which move each other shall continue to cause friction. In the context of machinery and metalworking, the event of friction is avoided because it will cause heat, wear, and will reduce machine energy [1-3]. In the power transmission system in an automotive engine, the friction will occur kinetic energy loss which lead to the increase of fuel consumption [4-5]. Another impact of friction is the conversion of energy into heat so that the machine is over heated. Lubrication is a way to reduce friction and wear by placing a thin layer (film) of fluid between surfaces that rub against each other [6], while the lubricant can be defined as a substance that is or inserted between two moving surfaces to reduce the its friction [7].

Lubricants consist of base oil added with selected chemicals called additives. Base oil or base lubricant is the biggest part of the lubricant, usually is the result of further processing of long residue generated in the process of distillation of crude oil in the CDU (crude distilling unit), or vegetable oils base. There are two basic types of lubricants based on mineral oil are

* Corresponding author. Tel/Fax : +62-251-831894

Email address : komar.sutriah@yahoo.com

Komar Sutriah et al. 
paraffinic base oil which is composed of straight-chain hydrocarbons and naphthenic base oil with naphthalene. Based on the viscosity index, base oil classified into high viscosity index (HVI), medium viscosity index (MVI), and low viscosity index (LVI) [8]. Lubricant additive is a chemical compound when added to base lubricating oil will increase the performance. The main function of lubricant additives such as detergents (dirt separator), viscosity index improver, anti-friction, anti-corrosion, or lowering the freezing point (pour point depressant). The ingredients are added in small amounts, for about $200 \mathrm{ppm}$ detergent functions, for cetane number enhancer between $0.1-0.5 \%$, about $50 \mathrm{ppm}$ for corrosion prevention and lubricity enhancing, and approximately $1 \%$ for anti-friction function [7].

Many compounds that can be used as a lubricant additive, including dithyocarbamate metal compounds, amines, phenolic, and dithyophosphate metal [9-10]. Conventional lubricant additives are usually chemical elements such as $\mathrm{Ba}, \mathrm{Ca}$, carbon, sulfur, $\mathrm{Zn}, \mathrm{Pb}, \mathrm{Mo}$, phosphorus, chlorine, siliconfats, polymers, and soap like compounds [5,11]. The compounds are commonly used as corrosion inhibitors and lubrication additives, based on the rate of decline effectiveness, namely class organophosphates, organocarboxylate acid and its salts, amide groups (RCONHR), and ester groups (RCOOR') with the alkyl chain length $(R)$ within range of C12-C18. Complex compound of Mo with monocarboxylic ligands, monoalkylation alkylene diamine, and glycerides reported a multifunctional additive in the lubrication system [12-13]. McConnachie et al. stated that Mo trinuclear complex compounds with dithiocarbamate ligands that function as anti-friction additives which can be produced in situ in a polar solvent systems such as toluene, tetrahydrofuran, dimethylformamide, methanol, or water [14]. Grossiord et al. in Asthana P stated that the methylene-bis-(di-n-butyldithyocarbamate) is an excellent anti-wear additive and good antioxidant properties [15]. Griffo \& Keshavan use additional substances such as Pb-diamildithyokarbamat, Mo-di-n-butyldithyocarbamate, Zn-dithyocarbamate, and $\mathrm{Sb}$-dithyocarbamate as anti-friction and anti-wear in rock bit high performance grease [16]. In addition, the compounds are commonly used as an additive in boundary lubrication system is a combination class of organosulphur or sulphur oxygen, organochlorines, organosulphur-chlorine, organophosphorus, organophosphorus-sulfur, esters of fatty acids, and a variety of organometallic compounds [17]. From various additives of phosphate, $\mathrm{Zn}$-dialkyldithyophosphate is the most commonly used, but due to environmental considerations phosphorus compounds lately, then dialkyldithyocarbamate compounds are used as an alternative to the dialkyldithyophosphate compounds.
Development of metal-dithyocarbamate complex compounds as lubricant additives and replace additive dithyophosphate and conventional additive of mixture of sulfur compounds, phosphate with metal, dithyocarbamate complex evidently indicate anti-friction better performance. Stability of metal-dithyocarbamate complexes allows its use at high temperature without system degradation. Metal-dithiocarbamate complex compounds are reported to have performance which reduce friction and improve friction coefficient stability is Zn-Mo-dithyocarbamate [18]. Mo combination with amine groups, alcohols, phosphine, ether, long chain carboxylic acids that form Mo mono-trinuclear complexes also been reported to have activity as a multi-functional additive in the lubrication system [10,12-13]. Dithyocarbamate organometallic compounds can also function as an antioxidant additive in lubrication systems [9,19-20].

However, most applications of alkyldithyocarbamate compounds are reported using a short chain alkyl group derived from mineral oils. Meanwhile if the alkyl chains in these compounds varied/replaced with long fatty acids alkyl chain (C12-C18) will increase compounds lipofility that will have implications for the increase in solubility in the lubricant base, and provide additional cushioning aspect that is expected to improve its performance as anti-friction/anti-wear than as an antioxidant. In a previous study of $\mathrm{Zn}$-difattyalkyldithyocarbamate has been successfully synthesized using raw material of vegetable oil-based primer fatty amine with a rendemen of $77-87 \%$ which depends on long-chain fatty acids, and are known to have excellent antioxidant activity [20]. In this research, we synthesized, test antifriction performance, and selection of the best variant of $\mathrm{Zn}$-difattyalkyldithyocarbamate meets the criteria as bi-functional additive anti-friction/anti-wear and antioxidant. Activity of vegetable oil-based $\mathrm{Zn}$ difattyalkyldithyocarbamate complex compounds hypothesized as an bi-functional additive, take the analogy and the starting point from expressions of $\mathrm{Zn}$ dialkyl/aryl dithyocarbamates compounds that have been prevalently used as boundary lubrication additive.

\section{EXPERIMENTAL SECTION}

\section{Materials}

The main materials used are: primary fatty amine (dodecylamine, hexadecylamine, octadecylamine), acylklorida (lauroyl chloride, palmitoyl chloride, oleoyl chloride), $\mathrm{LiAlH} 4$, tetrahydrofuran, diethylether, CS2, and $\mathrm{ZnCl} 2$ from E-Merck. In addition, the use 2 additives (anti-friction additive) of PetroLab Services Jakarta, 3 additives (extreme pressure additive) and lube 


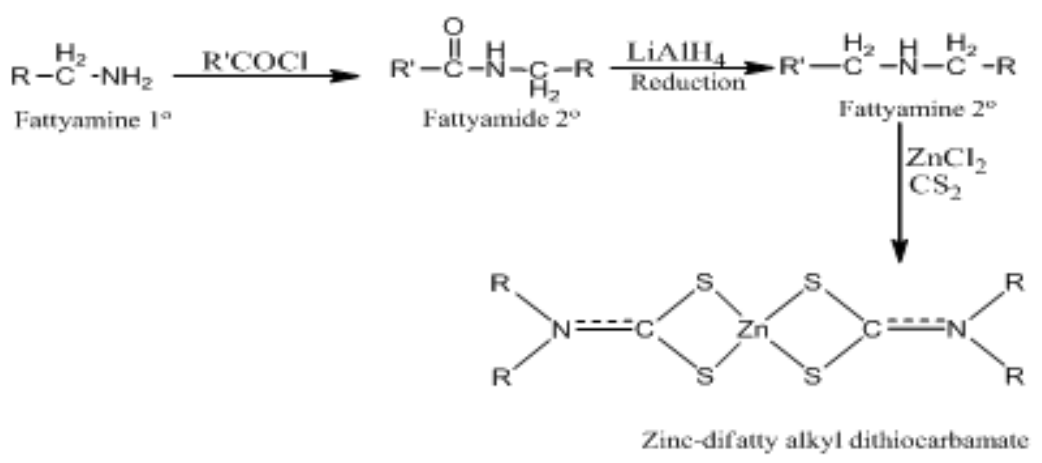

Fig 1. Synthesis of Zn-difattyalkyldithyocarbamate complex

base oil HVI-60 from the Product Development of Pertamina Laboratory, Jakarta.

\section{Instrumentation}

The main equipment used is closed Syncore stirred tank reactor, open stirred tank reactor, IR Prestige 21 Shimadzu Fourier transform (FTIR), and Four Balls Machine.

\section{Procedure}

Synthesis, separation, and monitoring the quality of Zn-difattyalkyldithyocarbamate products

Zn-difattyalkyldithyocarbamate synthesized from primary fatty amine through secondary fatty amide, and secondary fatty amine. The process of synthesis, separation and product quality monitoring of $\mathrm{Zn}$ difattyalkyldithyocarbamate carried out according to previous studies [20].

\section{Anti-wear/anti-friction test with four ball method}

Zn-difattyalkyldithyocarbamate product tested its anti-friction/anti-wear activity in the four ball machine by adding to the base oil lubricant HVI 60. Activity of antifriction/anti-wear measured from the magnitude of the pressure subject to the sample test which resulting friction and welding of steel balls in the four ball equipment through welding point performance indicators, and load wear index [21]. Synthesized additives mixed homogeneously with lubricant base oil HVI 60 to sample. Lubricant sample is poured into the four ball tool bowl until the three of steel balls submerged, the sample temperature inside the bowl is maintained between $18^{\circ} \mathrm{C}$ to $35^{\circ} \mathrm{C}$. The fourth ball is lowered into the bowl, loaded with certain weight $(\mathrm{Kg})$ is then rotated at a speed of $1,760 \pm 40 \mathrm{rpm}$ for $10 \mathrm{sec}$. Testing was repeated with gradually increasing load until a maximum load resulting in welding between the four steel balls. At each repetition of load, scratches diameter of steel bowl on the third sample is measured $(\mathrm{mm})$. Last load which lead to welding expressed as welding point $(\mathrm{Kg})$, while the data of the diameter of scratches is used to calculating load wear index.

\section{RESULT AND DISCUSSION}

\section{Synthesis Method Consistency}

Repetition of the synthesis of several variants product of Zn-difattyalkyldithyocarbamate produce the same yield level with previous studies, as well as product quality monitoring using FTIR, and HPLC showed good consistency of product quality in accordance with the results of previous studies [20].

Synthesis pathways of complex compounds Zn-long chain difattyalkyldithyocarbamate is presented in Fig. 1. The first step is synthesized of secondary fatty amines (difattyalkilamines) from primary fattyamines via intermediate secondary fatty amides. Secondary fatty amines then converted to $\mathrm{Na}$ difattyalkyldithyocarbamates hereinafter complexed with $\mathrm{Zn}^{2+}$ to form $\mathrm{Zn}$-difattyalkyldithyocarbamates. Difattyalkylamine and carbon disulfide are reacted to form difattyalkyldithyocarbamate and further reacted with $\mathrm{ZnCl}_{2}$ to form Zn-difattyalkyldithyocarbamate complex.

The synthesis progress of Zn-difattyalkyldithiocarbamate complex is monitored using FTIR. The important band of infrared absorption band of dithiocarbamate complex are $\vartheta(\mathrm{C}-\mathrm{N})$ and $\vartheta(\mathrm{C}-\mathrm{S})$. Uptake tioureida $\vartheta(\mathrm{C}-\mathrm{N})$ are usually located on the wave number of $1450-1550 \mathrm{~cm}^{-1}$ while the $\vartheta(C-S)$ are on the wave number of $950-1050 \mathrm{~cm}^{-1}$. Sharp absorption band at wave number of $1471-1478 \mathrm{~cm}^{-1}$ is the result of $\mathrm{C}-\mathrm{N}$ bond strain. The existence of this absorption band indicates that the ligand difattyalkyldithyocarbamate has acted as a bidentate ligand. Absorption band $\vartheta(\mathrm{C}-\mathrm{S})$ on the wave number of 952-957 $\mathrm{cm}^{-1}$ also shows that characterized dithyocarbamate as a bidentate ligand. Absorption band located in the far infrared region (400-300 $\mathrm{cm}^{-1}$ ) due to strain mode known as a metal-sulfur bond, $\vartheta(\mathrm{M}-\mathrm{S})[20]$. 


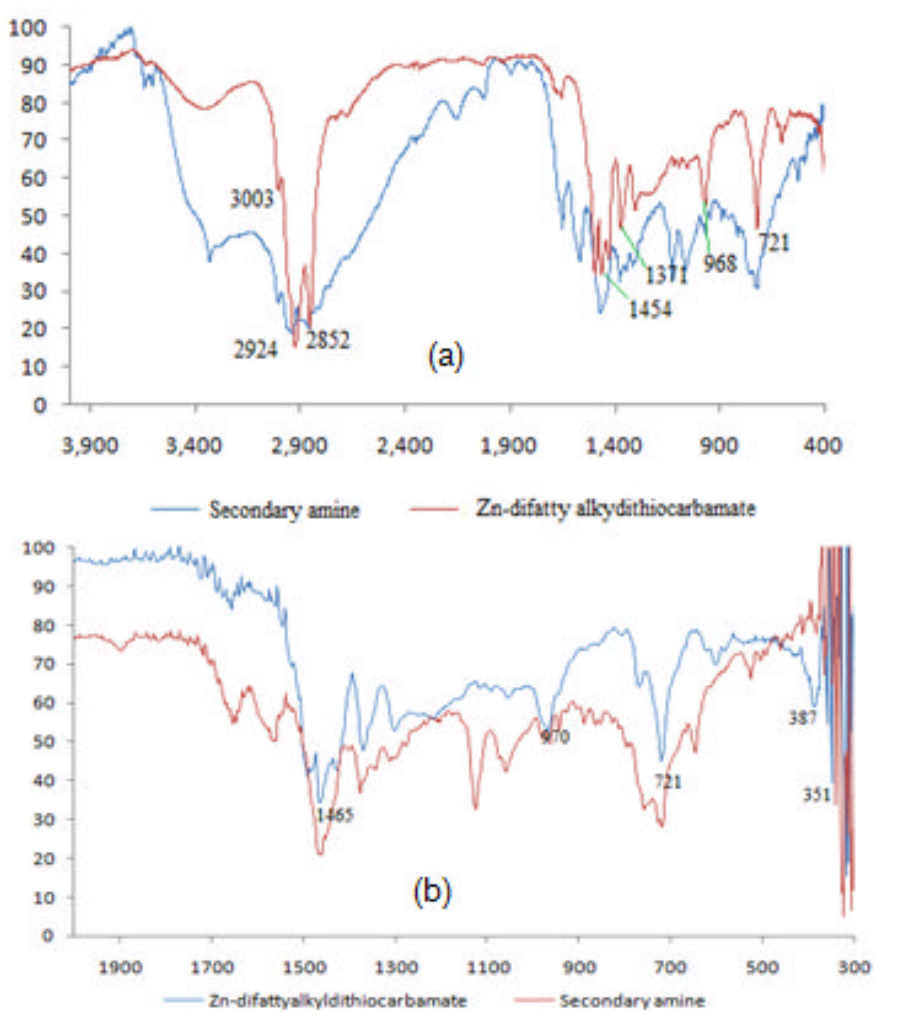

Fig 2. Absorption spectrum of a) IR and b) far IR of secondary fattyamina and Zn-difattyalkyldithyocarbamate

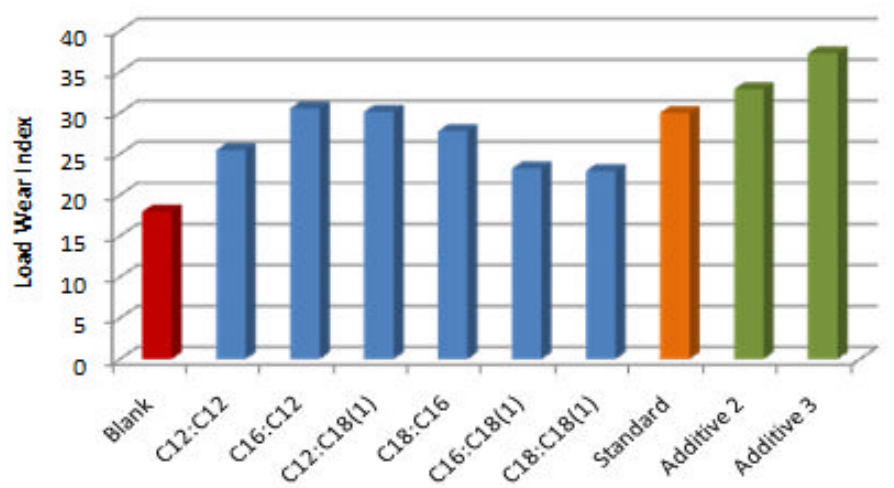

Fig 5. Load wear index of Zn-difattyalkyldithiocarbamate additive

The results indicate absorption band located in the infrared region of $2800-2950 \mathrm{~cm}^{-1}$ is corresponding to $\mathrm{CH}_{3}$ asymmetric stretch, 1454-1462 $\mathrm{cm}^{-1}$ shows C-N, and $968 \mathrm{~cm}^{-1}$ shows C-S group, this is characterized dithiocarbamate as a bidentate ligand. The presence of absorption band in the far infrared region, i.e. $351 \mathrm{~cm}^{-1}$ indicates the presence of $\mathrm{Zn}-\mathrm{S}$ bond. Fig. 2 show the IR absorption spectra of Zn-difattyalkyldithyocarbamate complex and secondary fatty amine [20].

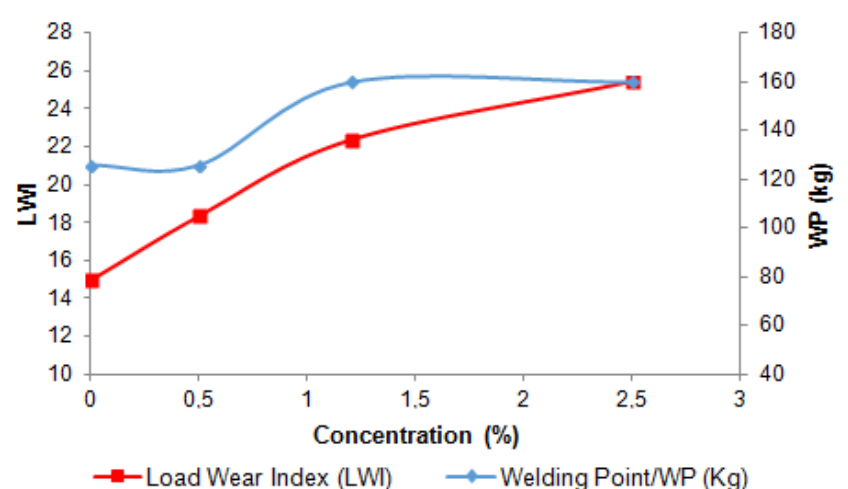

Fig 3. Zn-difattyalkyldithiocarbamate anti-friction antiwear power

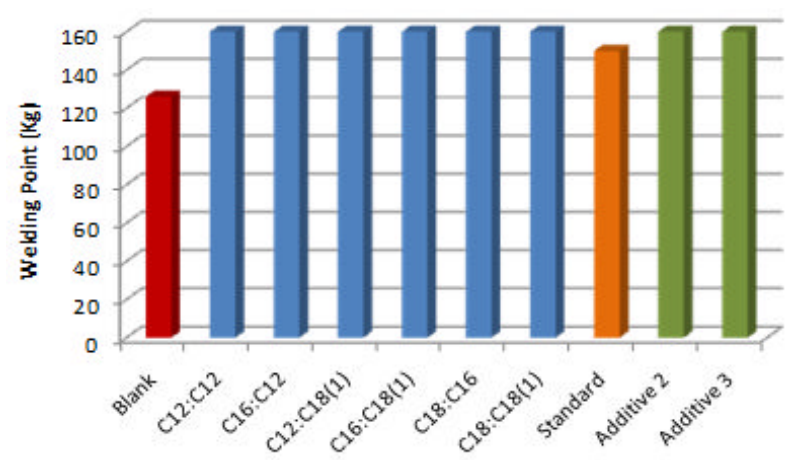

Fig 4. Welding point of Zn-difattyalkyldithiocarbamate additive

\section{Anti-Friction/Anti-Wear Power Testing}

Weld point is the highest load/pressure given to lubricants $(\mathrm{Kg})$ which produces steel balls welding which rotates between the three stationary steel balls, while the load wear index is the index of the ability of a lubricant to minimize the worn of the surface of the steel ball at the given load in the four ball machine. Load wear index is the average load values obtained from a series of repetitions of load variation is calculated by measuring the scratches diameter of the steel ball caused by any given load. The higher value of the both parameter, thus, the higher activity of its anti-friction/anti-wear, more effective as a lubricant in extreme pressure.

Initial stages of the anti-friction/anti-wear test on additive products of Zn-difattyalkyldithyocarbamate which is a range measuring verification four ball tool to obtain concentration ranges which provide a response/best measurement sensitivity for the tested additive product. On the measurement conditions, no matter how little difference response generated it is expected to be recorded, so that the effect of different alkyl chain length of additives in Zn-difattyalkyldithycarbamate products on its activity as 


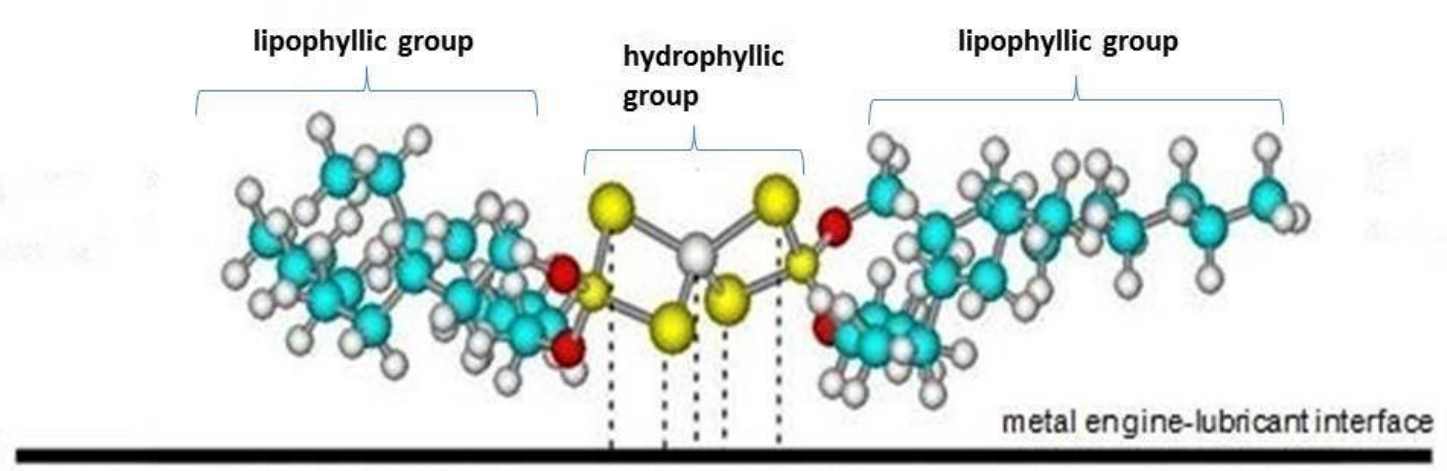

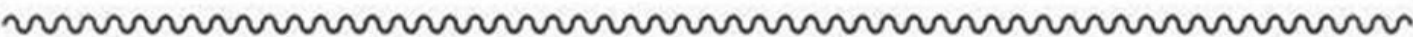

Fig 6. Adsoption model of $\mathrm{Zn}$-difattyalkyldithyocarbamate act as surfactants on metal engine-lubricant interface

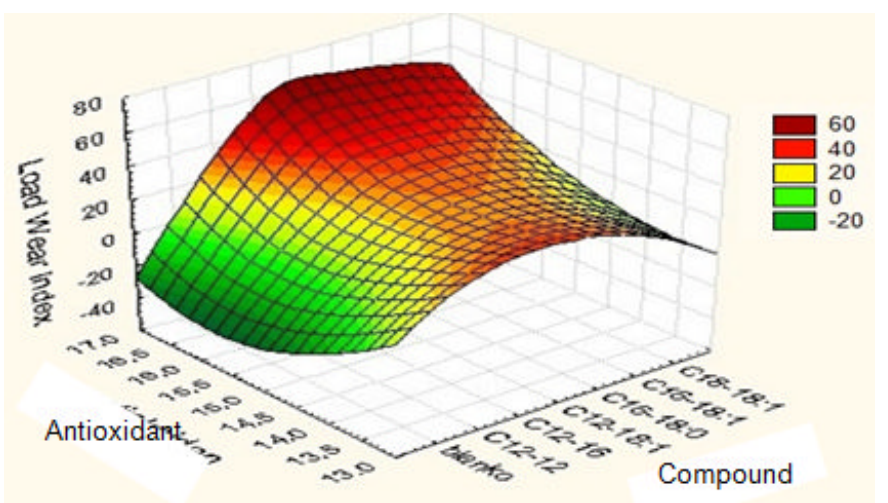

Fig 7. Contour of performance surface Zn-difattyalkyldithyocarbamate additives

anti-friction/anti-wear can be accurately mapped. Verification results of welding points and load wear index in the range of additive concentration of $0-2.5 \%(\mathrm{w} / \mathrm{w})$ which shown in Fig. 3.

Fig. 3 shows the increase of weld point number which greater with the increase of concentration/dose of used additives. At low concentrations, the antifriction/anti-wear activity rise up with the increase in the concentration reaches a certain critical concentration, but further concentration increase do not give power significant anti-friction/anti-wear. The same thing happened with the load wear index, although the curve is not very clearly shows the critical concentration. Of the weld point curve in Fig. 3 it appears that the efficient and effective critical concentration provides anti-friction/antiwear response of $1.2 \%(\mathrm{w} / \mathrm{w})$. Measurement results of welding point and load wear index value to 6 variants of Zn-difattyalkyldithyo-carbamate additive products, and comparative commercial additives 2, commercial additives 3 , at a concentration of $1.2 \%$ shown in Fig. 4 and 5 .

As shown in Fig. 4 and 5, all variants activity of Zndifattyalkyldithyocarbamate additive shows antifriction/anti-wear indicated by the value of load wear index and welding points higher than the base lubricant blank HVI 60. Of the two test parameters used as indicators of performance, there is only load wear index which gives different responses to different lengths of alkyl chains in tested Zn-difattyalkyldithyocarbamate additive products. Welding point of all variants of the $\mathrm{Zn}$-difattyalkyldithyocarbamate additive and commercial additives tested with the same value, i.e. $160 \mathrm{~kg}$, and just different (higher) than the base lubricant blank HVI 60 is $126 \mathrm{~kg}$. From Fig. 5 it appears that $\mathrm{Zn}$-bis (laurilpalmityl)dithyocarbamate (C12-C16) has the highest value of load wear index than five other variants of Zn-difattyalkyldithyocarbamate, although the value is still lower than the 2 commercial additive products for comparison. When compared to the US Steel 136 standard which is one of the hydraulic additives standard of extreme pressure which set minimum load wear index and the welding point of $30 \mathrm{~kg}$ and $150 \mathrm{~kg}$ [22], then the two variants of Zn-bis(laurylpalmityl)dithyocarbamate additive, and Zn-bis(lauryloleyl)dithyocarbamate meet the standard criteria.

Anti-friction/anti-wear activity indicated by $\mathrm{Zn}$ difattyalkyldithyocarbamate compounds product is an expression of the character of these compounds which classified as surfactants. Zn-dithyo group is part to hydrophilic compound which shall be oriented and adsorbed to metal engine-lubricant interface, whereas the fatty acid alkyl is part of lipophilic that will go into the bulk of lubricants liquid. $\mathrm{Zn}$ difattyalkyldithyocarbamate molecule will form a monolayer adsorption layer massively on the metallubricant interface, and will be an effective barrier interface, acting as a cushion that will withstand friction between metal surfaces thus serves to reduce metal wear due to friction. Adsoption model of $\mathrm{Zn}$ difattyalkyldithyocarbamate surfactants on metal engine-lubricant interface shown in Fig. 6.

The addition of the alkyl chain length of $\mathrm{C} 12-\mathrm{C} 12$ to $\mathrm{C} 12-\mathrm{C} 16$, contribute positively to the increase in load wear index, but further increase in the alkyl chain of C12-C16 to C12-C18:1, C12-C18:1 to C16-C18:1 to C18-C18:1 resulted in decreased load wear index. 
Previous studies indicated that the presence of double bonds in the additive $\mathrm{Zn}$-difattyalkyldithyocarbamate has positive effect on the increase in antioxidant power [20], contrary to the prevailing anti-friction. The presence of the double bond causes a decrease in load wear index so that the $\mathrm{C} 16-\mathrm{C} 18$ has a load wear index value higher than the C16-C18:1, while the influence of symmetry in the alkyl chain length of the additive compound to antifriction power is not recorded on the obtained test performance.

Load wear index of six variant of $\mathrm{Zn}$ difattyalkyldithyocarbamate additives is lower and significantly different from the 2 commercial additive products at a confidence level of $95 \%$ based on the Tukey's test using SPSS 10:00. However, the six variant of the additives has a highest load wear index value and significantly different from the base oil blank $60 \mathrm{HVI}$ at 95\% confidence level $(P<0.05), \quad Z n$-bis(laurylpalmityl) dithyocarbamate and Zn-bis (lauryloleyl)dithyocarbamate additives is an additive variant with the highest load wear index, the two are not significantly different at the $95 \%$ confidence level, but both are significantly different from other additives variants.

Obtained from previous research that Zn-bis(dilauryl)dithyocarbamate an additive variant that has the highest antioxidant activity [20], while the highest power of the anti-friction/anti-wear study filled by a Zn-bis(lauryl palmityl)dithyocarbamate variant. Fig. 7 presents the contours of the surface of anti-friction/antiwear and antioxidant activity as a function of long-chain fatty acids in the Zn-difattyalkyldithyocarbamate complex obtained from the results of previous studies and this study.

Anti-friction/anti-wear power of Zn-bis(dilauryl) dithyocarbamate is lower and significantly different from the Zn-bis(laurylpalmityl)dithyocarbamate, Zn-bis(lauryl palmityl)dithyocarbamate antioxidant power is lower and also significantly different from Zn-bis (dilauryl)dithyocarbamate at the $95 \%$ confidence level. These facts indicate no additive variant which also has maximum antioxidant and anti-friction/ anti-wear activity. However, as shown in Fig. 7, it can be stated that the Zn-bis(lauryl palmityl)dithyocarbamate additive is an additive variant that has optimum performance, can double as an antioxidant, and anti-friction/anti-wear, which are not shown by commercial additives 2, and 3. As antifriction/anti-wear additive, additive 2 does have a dominant performance, but does not show the antioxidant activity even lower the antioxidants, the same thing applies to additive 3 . Antioxidant activity of additive 3 and additive 2 is lower than the form of RBDPO [19]. This fact reinforces the empirical evidence in the market that there is no additive which is multifunctional commercialized, while Zn-bis(lauryl palmityl)dithyocarbamate shows promise as an additive that has the performance as a powerful antioxidant and also can serve as anti-friction/anti-wear.

\section{CONCLUSION}

Complex compounds of Zn-difattyalkyldithyocarbamate have activity as an anti-friction/anti-wear additive, as well as an antioxidant additive. Zn-bis(laurylpalmityl)dithyocarbamate $\quad(\mathrm{C} 12-\mathrm{C} 16)$ is product variant that has the anti-friction/anti-wear highest power among the other five variants of $\mathrm{Zn}$ difattyalkyldithyocarbamate, with the load wear index value of 30.53 and a welding point of $160 \mathrm{~kg}$ that meet the U.S. Steel 136 standards as an extreme pressure additive. Zn-bis(laurylpalmityl)dithyocarbamate meet the criteria as a bi-functional lubricant additive, as an anti-friction/anti-wear and antioxidant additive.

\section{ACKNOWLEDGEMENT}

This work facilitated by the Integrated Laboratory of the Bogor Agriculture University and Lubricant Product Development of Pertamina Laboratory, Jakarta.

\section{REFERENCES}

1. Hu, J-Q., Hu, Y-Q., Du. Z-H., and Liu, C-C., 2007, Pet. Coal, 49 (2), 80-85.

2. Martin, J-M., Grossiord, C., Varlot, K., Vacher, B., and Igarashi, J., 2000, Tribol. Lett., 8 (4), 193-201.

3. Minami, I., Murakami, H., Nanao, H., and Mori, S., 2006, J. Jpn. Pet. Inst., 5, 268-273.

4. Kurth, T.L., Biresaw, G., and Adhvaryu, A., 2005, J. Am. Oil Chem. Soc., 82 (4), 293-299.

5. Miller, R.W., 1993, Lubricants and Their Applications, McGraw-Hill, Inc, New York.

6. Masjuki, H.H., Maleque, M.A., Kubo, A., and Nonaka, T., 1999, Tribol. Int., 32 (6), 305-314.

7. Taher, M., 2011, Tribological performance of novel boron dithiocarbamate lubricant additives, Thesis, Lulea University of Technology.

8. Sharma, B.K., Adhvaryu, A., and Erhan, S.Z., 2009, Tribol. Int., 42 (2), 353-358.

9. Gogoi, P.K., and Sonowal, J., 2005, Indian. J. Chem.Technol., 12, 50-54.

10. Stiefel, 2001, U.S Patent, 6232276.

11. Pottuz, L.J., Vacher, B., Ohmae, N., Martin, J.M., and Epicier, T., 2008, Tribol. Lett., 30 (1), 69-80.

12. Gatto, V.J., 2003, U.S. Patent, 6509303.

13. Gatto, V.J., 2003, U.S. Patent, 664592.

14. McConnachie, J.M., 2003, U.S. Patent, 6569820.

15. Asthana, P., 2006, Micro-and Nano-Scale Experimental Approach to Surface Engineer Metals, Thesis, Texas A\&M University. 
16. Griffo, A., and Keshavan, M.K., 2007, U.S. Patent, 20070254817 A1.

17. Rizvi, S.Q.A., 1992, "Lubricant Additive and Their Function", in ASM Handbook, Friction, Lubrication, and Wear Technology, Jl. 18 ASM International.

18. Iwasaki, H., Koganei, K., and Nakanishi, H., 2000, U.S. Patent, 6096693.

19. Kaludjerovic, G.N., Djinovic, V.M., Trifunovic, S.R., Hodzic, I.M., and Sabo, T.J., 2002, J. Serb. Chem. Soc., 67 (2), 123-126.
20. Sutriah, K., Mas'ud, Z.A., and Irawadi, T.T., 2012, Indo. J. Chem., 12 (2), 189-194.

21. [ASTM], American Standard Test Method, 2006, Standard Test Method for Measurement of Extreme-Pressure Properties of Lubricating Fluids (Four-Ball Method), Philadelphia.

22. Duncan, C., Reyes-Gavilan, J., Costantini, D., and Oshode, S., 2002, Lubrication Enginering, 18-28. 